Article

\title{
A Unified Model for the Prediction of Yield Strength in Particulate-Reinforced Metal Matrix Nanocomposites
}

\section{F. A. Mirza and D. L. Chen *}

Department of Mechanical and Industrial Engineering, Ryerson University, 350 Victoria Street, Toronto, ON M5B 2K3, Canada; E-Mail: f4mirza@ryerson.ca

* Author to whom correspondence should be addressed; E-Mail: dchen@ryerson.ca; Tel.: +1-416-979-5000 (ext. 6487); Fax: +1-416-979-5265.

Academic Editor: Geminiano Mancusi

Received: 9 July 2015 / Accepted: 5 August 2015 / Published: 10 August 2015

\begin{abstract}
Lightweighting in the transportation industry is today recognized as one of the most important strategies to improve fuel efficiency and reduce anthropogenic climate-changing, environment-damaging, and human death-causing emissions. However, the structural applications of lightweight alloys are often limited by some inherent deficiencies such as low stiffness, high wear rate and inferior strength. These properties could be effectively enhanced by the addition of stronger and stiffer reinforcements, especially nano-sized particles, into metal matrix to form composites. In most cases three common strengthening mechanisms (load-bearing effect, mismatch of coefficients of thermal expansion, and Orowan strengthening) have been considered to predict the yield strength of metal matrix nanocomposites (MMNCs). This study was aimed at developing a unified model by taking into account the matrix grain size and porosity (which is unavoidable in the materials processing such as casting and powder metallurgy) in the prediction of the yield strength of MMNCs. The Zener pinning effect of grain boundaries by the nano-sized particles has also been integrated. The model was validated using the experimental data of magnesium- and titanium-based nanocomposites containing different types of nano-sized particles (namely, $\mathrm{Al}_{2} \mathrm{O}_{3}, \mathrm{Y}_{2} \mathrm{O}_{3}$, and carbon nanotubes). The predicted results were observed to be in good agreement with the experimental data reported in the literature.
\end{abstract}

Keywords: metal matrix nanocomposites; Orowan strengthening effect; Hall-Petch relationship; Zener pinning effect 


\section{Introduction}

Lightweighting in ground vehicles is deemed as one of the most effective strategies to improve fuel economy and reduce anthropogenic climate-changing, environment-damaging, costly, and human death-causing emissions [1-7] due to the tremendous environmental concerns. To manufacture lightweight vehicles, advanced high-strength steels, aluminum alloys, magnesium $(\mathrm{Mg})$ alloys, and polymers are being used in the automotive and aerospace sectors, but substantial weight reductions could be further achieved by employing ultra-lightweight $\mathrm{Mg}$ alloys due to their low density, high strength-to-weight ratio, and superior damping capacity [1,4,8,9]. However, the applications of $\mathrm{Mg}$ alloys are often restricted by some inherent deficiencies such as low stiffness, high wear rate, and inferior creep resistance or mechanical strength at elevated temperatures [10,11]. Reinforcement with a discontinuous phase especially nano-sized particles has been considered to be the most favored choice by researchers in recent years to improve physical, mechanical, and damping properties of $\mathrm{Mg}$ beyond the limits dominated by traditional alloying [11-19].

In the past few years, several studies have been done to develop constitutive relationships that can be used to predict the mechanical properties of metal matrix nanocomposites (MMNCs) as a function of the reinforcement, matrix, and processing conditions [10,15,20-27]. Ramakrishnan [20] predicted the yield strength of micro-sized particulate-reinforced metal matrix composites (MMCs), using a composite sphere model for the intra-granular type of MMCs and incorporating two improvement parameters associated with the dislocation strengthening of the matrix and the load-bearing effect of the reinforcement. Recently, Zhang and Chen [10,21] predicted the yield strength of MMNCs via considering the Orowan strengthening mechanism, enhanced dislocation density due to the mismatch of coefficients of thermal expansion (CTE) between the reinforcement and matrix, and load-bearing effect which has been used by many researchers, e.g., [15,23-27], to predict the yield strength of particulate-reinforced MMNCs. However, in all of the above models no effect of porosity was taken into account, which could lead to an overestimate of the yield strength of composites. In the composite processing (casting, powder metallurgy, electrodeposition, plasma and cold spray, etc.), the complete elimination of porosity is either difficult or impossible [28-37]. Porosity is among the dominant factors causing failure of discontinuous reinforced metal matrix composites (DRMMCs) in the tensile tests [17]. The commonly encountered spherical pores or gas porosity are observed to create stress concentrations and thus lead to failure. The ductility and toughness of most metal based composites are influenced by the presence of voids and the balance between reinforcing particles sharing the load [14]. The large amount of porosity associated with oxides is often surrounded by either individual or clusters of reinforcement particles, which significantly decreases the mechanical properties of DRMMCs [32]. Also, it was reported that the presence of nanoparticles led to a higher level of porosity and more irregular pores with bigger pore size in the nanocomposites [34]. Thus, it is necessary to consider the effect of porosity on the mechanical properties of nanocomposites.

Furthermore, very limited investigations have been reported to account for the influence of matrix grain size in the MMNCs, while the relation between the yield or flow stress and grain size in polycrystalline alloys was well established by Hall and Petch [38,39]. Recrystallization studies in DRMMCs have shown that the nucleation potency increases with increasing reinforcement size and volume fraction, called particle stimulated nucleation (PSN) [40,41]. It would be expected that the 
nucleation density is high and the recrystallized grain size is smaller than the interparticle spacing, since normal grain growth continues after complete recrystallization until the grain boundaries are pinned by the reinforcement particles. As reported by Hassold et al. [42], the inert, second-phase particles can inhibit grain growth and lead to a pinned microstructure where grain growth ceases (as shown in Figure 1). Most particles are located on the grain boundaries, which are strongly pinned by the particles. The grain boundaries are highly non-random in location and the particles are more closely spaced as the volume fraction increases. Also, the pinned grain size decreases with increasing volume fraction of particles (Figure 1b). Zener [40-45] first observed this effect, commonly called Zener pinning (or Zener drag) [41,45], and predicted the dependence of the pinned grain size on the volume fraction and radius of the particles. The presence of Zener pinning in the MMNCs will further decrease the matrix grain size, depending on the second-phase particles size and volume fraction. The objective of this study was, therefore, to develop a unified model of integrating all the above strengthening effects to achieve a more accurate prediction of the yield strength of MMNCs, which was then validated using the experimental data of magnesium-based nanocomposites available in the literature.

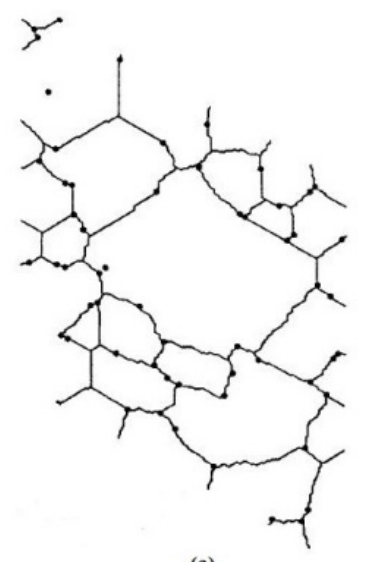

(a)

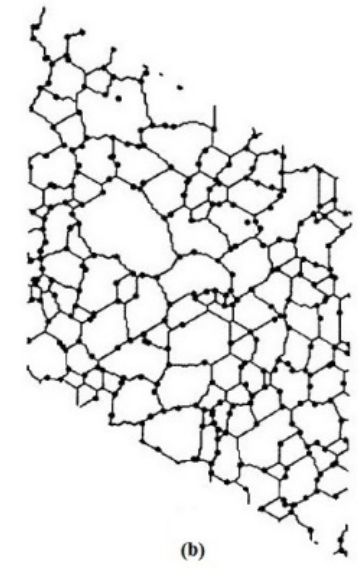

(b)

Figure 1. Pinned microstructures of nanocomposites for two volume fractions of particles of (a) $V_{\mathrm{p}}=0.01$ and (b) $V_{\mathrm{p}}=0.05[42]$.

\section{Model Development}

To facilitate a better understanding of an analytical model for predicting the yield strength of MMNCs, a brief review on the underlying factors affecting the yield strength of composites is given as follows.

\subsection{Load Transfer to the Reinforcement Particles}

Due to the nano-size of the reinforcement particles and the sound synthesizing methods, there is a strong cohesion at the atomic level between the matrix and nano-sized particles, i.e., the nano-sized particles are directly bonded to the matrix $[10,12,20-22,46]$. Then the nano-sized particles would carry a certain portion of load depending on the volume fraction, giving rise to some degree of load transfer between matrix and reinforcement [10,21,22]. Provided that the porosity is present in the composites, the porosity would affect the load-bearing term. Thus, the improvement factor associated with the load-bearing effect of reinforcement in the presence of porosity can be derived as [46], 


$$
f_{1}=\frac{1}{2} V_{\mathrm{p}}-P
$$

where $f_{1}$ is an improvement factor associated with load-bearing effect, $P$ is the volume fraction of porosity, and $V_{\mathrm{p}}$ is the volume fraction of the reinforcement nano-particles.

\subsection{Dislocation Density}

In MMNCs, the increased interfacial area between the reinforcement and matrix contributes to the enhanced mechanical properties due to the presence of nano-sized particles [10,21]. Also, thermal mismatch dislocations in the matrix around the nano-sized particles would be generated to relieve the thermal stresses occurred at the interface during cooling from the processing temperature. The thermal stresses around the nanoparticles would be large enough to induce plastic deformation in the matrix near the interface region $[13,47,48]$. The improvement factor related to the dislocation density in the matrix, $f_{\mathrm{d}}$ can be expressed as follows $[10,21,46]$,

$$
\begin{gathered}
f_{\mathrm{d}}=k G_{\mathrm{m}} b \sqrt{\rho} / \sigma_{\mathrm{ym}} \\
\rho=\frac{12 \Delta \alpha \Delta T V_{\mathrm{p}}}{b d_{\mathrm{p}}\left(1-V_{\mathrm{p}}\right)}
\end{gathered}
$$

where $\sigma_{\mathrm{ym}}$ is the yield strength of the monolithic matrix without any porosity, $G_{\mathrm{m}}$ is the shear modulus of the matrix, $b$ is the Burgers vector of the matrix, $k$ is a constant (approximately equal to 1.25, based on the theoretical estimates in reference [10]), $\rho$ is the enhanced dislocation density due to the difference in the coefficients of thermal expansion between the reinforcement phase and the matrix $(\Delta \alpha), d_{\mathrm{p}}$ is the particle size, and $\Delta T$ is the difference between the processing and test temperatures.

\subsection{Orowan Strengthening}

In the precipitation-hardened alloys the internally precipitated nano-sized particles are proven to be either sheared (for smaller and softer particles) or by-passed by dislocations (i.e., Orowan strengthening mechanism of dislocation bowing) for larger and harder particles [37]. In the case of MMNCs where the hard and external nano-sized particles are added, it would be reasonable to assume that the Orowan strengthening mechanism would occur [10,21]. The improvement factor related to the Orowan strengthening of nanoparticles added, forowan can be expressed as follows $[10,21,46]$,

$$
\begin{gathered}
f_{\text {Orowan }}=\frac{0.13 G_{\mathrm{m}} b}{\lambda \sigma_{\mathrm{ym}}} \ln \frac{r}{b} \\
\lambda \approx d_{\mathrm{p}}\left[\left(\frac{1}{2 V_{\mathrm{p}}}\right)^{\frac{1}{3}}-1\right]
\end{gathered}
$$

where $r$ is the particle radius $\left(r=d_{\mathrm{p}} / 2\right)$, and $\lambda$ is the interparticle spacing. 


\subsection{Porosity}

As mentioned above, some inherent characteristics such as porosity were inevitably present in MMNCs which would have a significant effect on the yield strength of MMNCs [28-37]. For example, the occurrence of porosity as discontinuities in cast MMC interrupted the balance between the reinforcing particles carrying the load, generated a stress concentration and facilitated the crack initiation and propagation, and thus reduced its mechanical properties [32]. Also, most fatigue cracks initiated from the discontinuities in materials, mainly in the highly stressed regions of components. With increasing volume fraction of reinforcement particles, the likelihood of forming the processing-induced voids became higher, leading to a degradation of the yield strength [12]. Accordingly, it is necessary to consider the effect of porosity in more realistically predicting the yield strength of MMNCs. Based on our previous publication [46], $f_{\text {porosity }}$ is the deterioration factor associated with the presence of porosity in MMNCs, which could be expressed as [29],

$$
f_{\text {porosity }}=1-e^{-n P}
$$

where $n$ is an empirical constant depending on the porosity characteristics such as pore size, geometry, and orientation [29]. If the average pore shape was assumed to be close to cylinder orientated between $45^{\circ}$ and $90^{\circ}$ with respect to the loading axis, $n$ could be estimated as [29],

$$
n=0.405 \mathrm{l} / d_{\mathrm{p}}+0.318 \mathrm{~d} / \mathrm{l}+1.22
$$

where $l$ is the length of the particle, respectively.

Based on the above mechanisms, the concept of multiplication as reported by Zhang and Chen [10,21], now referred to as the "Zhang and Chen method", "Zhang and Chen approach", "Zhang and Chen model", or "Zhang and Chen (ZC) summation method", e.g., in [26,49-53], was used to account for both additive and synergistic effects of the strengthening and weakening factors, and a further modified analytical model for predicting the yield strength of MMNCs with consideration of the effect of porosity was proposed as follows [46],

$$
\sigma_{\mathrm{yc}}=\sigma_{\mathrm{ym}}\left(1+f_{1}\right)\left(1+f_{\mathrm{d}}\right)\left(1+f_{\text {Orowan }}\right)\left(1-f_{\text {porosity }}\right)
$$

where $\sigma_{\mathrm{yc}}$ is the yield strength of MMNCs. It should be noted that since the yield strength of MMNCs is considered in this model, no strain hardening effect during the subsequent plastic deformation beyond yielding is taken into account.

\subsection{Effects of Grain Size on the Yield Strength of MMNCs}

The influence of grain size on the mechanical properties is complex since the grain boundaries may either act as obstacles to dislocation slip (strengthening effect) or provide a positive contribution to the deformation of the material (softening effect). However, the following well-known Hall-Petch relation between the yield stress and grain size was proposed [38,39,54],

$$
\sigma_{\mathrm{YS}}=\sigma_{\mathrm{o}}+k d^{-1 / 2}
$$

where $d$ is the grain size, $k$ and $\sigma_{o}$ are constants. This equation was revisited Li et al. in terms of the collective motion of interacting dislocations and rearranged as follows [55], 


$$
\sigma_{\mathrm{YS}}=\sigma_{\mathrm{o}}+K G \sqrt{b / d}
$$

where $K$ is constant, $G$ is the shear modulus, and $b$ is the burgers vector. The typical value of $K$ for pure fcc metals is 0.05 to 0.5 [54,56].

As mentioned earlier, the second-phase particles can impede grain growth and lead to a pinned microstructure where grain growth ceases [40]. The dependence of the pinned grain size on the volume fraction and radius of the particles could be expressed as follows [40,42-44],

$$
R=\frac{4 r_{\mathrm{p}}}{3 V_{\mathrm{p}}}
$$

where $R$ is the matrix grain radius. By combining Equations (6a) and (7), a modified Hall-Petch equation with consideration of Zener pinning is obtained as follows,

$$
\sigma_{\mathrm{YS}}=\sigma_{\mathrm{o}}+K G \sqrt{b /\left(\frac{4 d_{\mathrm{p}}}{3 V_{\mathrm{p}}}\right)}
$$

and the improvement factor can be expressed as,

$$
f_{\text {Hall-Petch-Zener }}=\Delta \sigma_{\text {Hall-Petch-Zener }} / \sigma_{\text {ym }}
$$

where $\Delta \sigma_{\text {Hall-Petch-Zener }}$ is,

$$
\Delta \sigma_{\text {Hall-Petch-Zener }}=K G_{\mathrm{m}} \sqrt{\frac{3 b V_{\mathrm{p}}}{4 d_{\mathrm{p}}}}
$$

Based on this additional consideration of the grain growth retardation by dispersed-particle-pinning of grain boundaries, the analytical model for predicting the yield strength of MMNCs becomes,

$$
\sigma_{\mathrm{yc}}=\sigma_{\mathrm{ym}}\left(1+f_{1}\right)\left(1+f_{\mathrm{d}}\right)\left(1+f_{\text {Orowan }}\right)\left(1+f_{\text {Hall-Petch-Zener }}\right)\left(1-f_{\text {Porosity }}\right)
$$

Now substituting Equations (1)-(4a) and (9) into Equation (10) and considering $\Delta T=T_{\text {process }}-T_{\text {test }}$ and $\Delta \alpha=\alpha_{\mathrm{m}}-\alpha_{\mathrm{p}}$ (the difference in the coefficients of thermal expansion between the reinforcement phase and the matrix), the following equation for the yield strength of MMNCs can be derived,

$$
\sigma_{\mathrm{yc}}=\left(1+0.5 V_{\mathrm{p}}-P\right)\left(\sigma_{\mathrm{ym}}+A+B+\frac{A B}{\sigma_{\mathrm{ym}}}\right)\left(1+\frac{C}{\sigma_{\mathrm{ym}}}\right) e^{-n P}
$$

where $A, B$, and $C$ can be expressed as follows,

$$
\begin{gathered}
A=1.25 G_{\mathrm{m}} b \sqrt{\frac{12\left(T_{\text {process }}-T_{\text {test }}\right)\left(\alpha_{\mathrm{m}}-\alpha_{\mathrm{p}}\right) V_{\mathrm{p}}}{b d_{\mathrm{p}}\left(1-V_{\mathrm{p}}\right)}} \\
B=\frac{0.13 G_{\mathrm{m}} b}{d_{\mathrm{p}}\left[\left(\frac{1}{2 V_{\mathrm{p}}}\right)^{\frac{1}{3}}-1\right]} \ln \frac{d_{\mathrm{p}}}{2 b}
\end{gathered}
$$




$$
C=K G_{\mathrm{m}} \sqrt{\frac{3 b V_{\mathrm{p}}}{4 d_{\mathrm{p}}}}
$$

\section{Results and Model Validation}

First of all, the individual contribution of all improvement factors (using Equations (1)-(3) [10,21,46], and (9)) with respect to the size and volume fraction of nanoparticles in $\mathrm{Mg} / \mathrm{Al}_{2} \mathrm{O}_{3}$ nanocomposites is identified and plotted in Figures 2 and 3. Considering $V_{\mathrm{p}}+V_{\mathrm{m}}+P=1$ and substituting Equation (4a) into Equation (4), the following equation for $f_{\text {porosity }}$ can be derived,

$$
f_{\text {porosity }}=1-e^{-\left(0.405 / / d_{\mathrm{p}}+0.318 d_{\mathrm{p}} / l+1.22\right)\left(1-V_{\mathrm{p}}-V_{\mathrm{m}}\right)}
$$

where $V_{\mathrm{m}}$ is the volume fraction of matrix. Figure 2 shows the variation of the improvement factors with the nanoparticle size with specific volume fractions of 0.03 and 0.01 for nanoparticles and porosity in $\mathrm{Mg} / \mathrm{Al}_{2} \mathrm{O}_{3}$ nanocomposites as an example. It is seen that the contributions of $f_{1}$ and $f_{\text {porosity }}$ are fairly small; the contributions of $f_{\mathrm{d}}, f_{\text {Orowan, }}$ and $f_{\text {Hall-Petch-Zener }}$ are relatively large and in the sequence of $f_{\mathrm{d}}>f_{\text {Orowan }}>f_{\text {Hall-Petch-Zener }}$ which increase monotonically and strongly with decreasing size of nanoparticles. It is also observed that $f_{\text {Orowan }}$ and $f_{\text {Hall-Petch-Zener }}$ increase more rapidly when the nanoparticle size becomes very small (e.g., $<50 \mathrm{~nm}$ ). As seen from Figure 3 the change of the improvement factors with the volume fraction of nanoparticles illustrates similar findings. That is, $f_{i}$ and $f_{\text {porosity }}$ do not exhibit a significant influence, while $f_{\mathrm{d}}, f_{\text {Orowan, }}$ and $f_{\text {Hall-Petch-Zener monotonically increase }}$ with increasing volume fraction of nanoparticles in the same order of $f_{\mathrm{d}}>f_{\text {Orowan }}>f_{\text {Hall-Petch-Zener. }}$

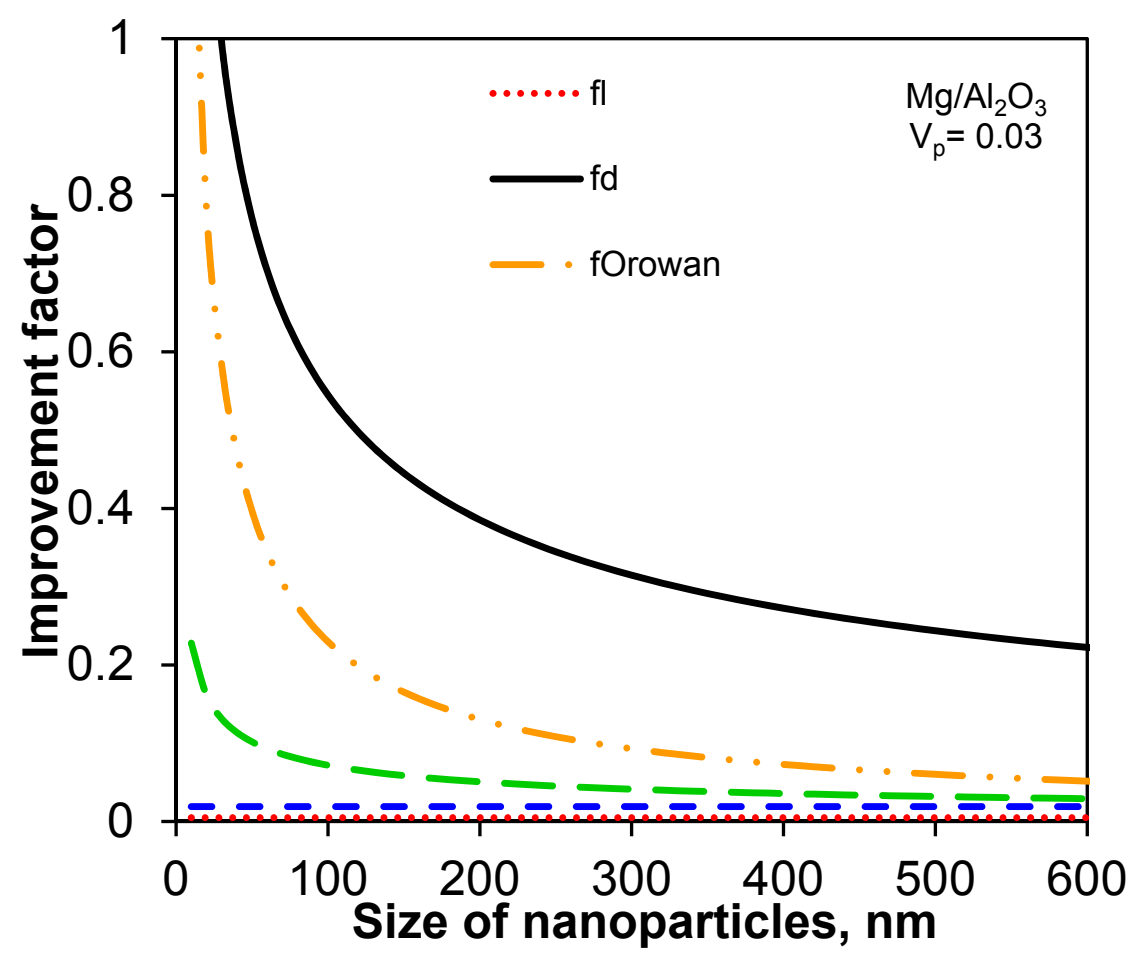

Figure 2. The improvement factors as a function of nanoparticle size with a volume fraction of 0.03 and 0.01 for nanoparticles and porosity, respectively, in $\mathrm{Mg} / \mathrm{Al}_{2} \mathrm{O}_{3}$ nanocomposites. 


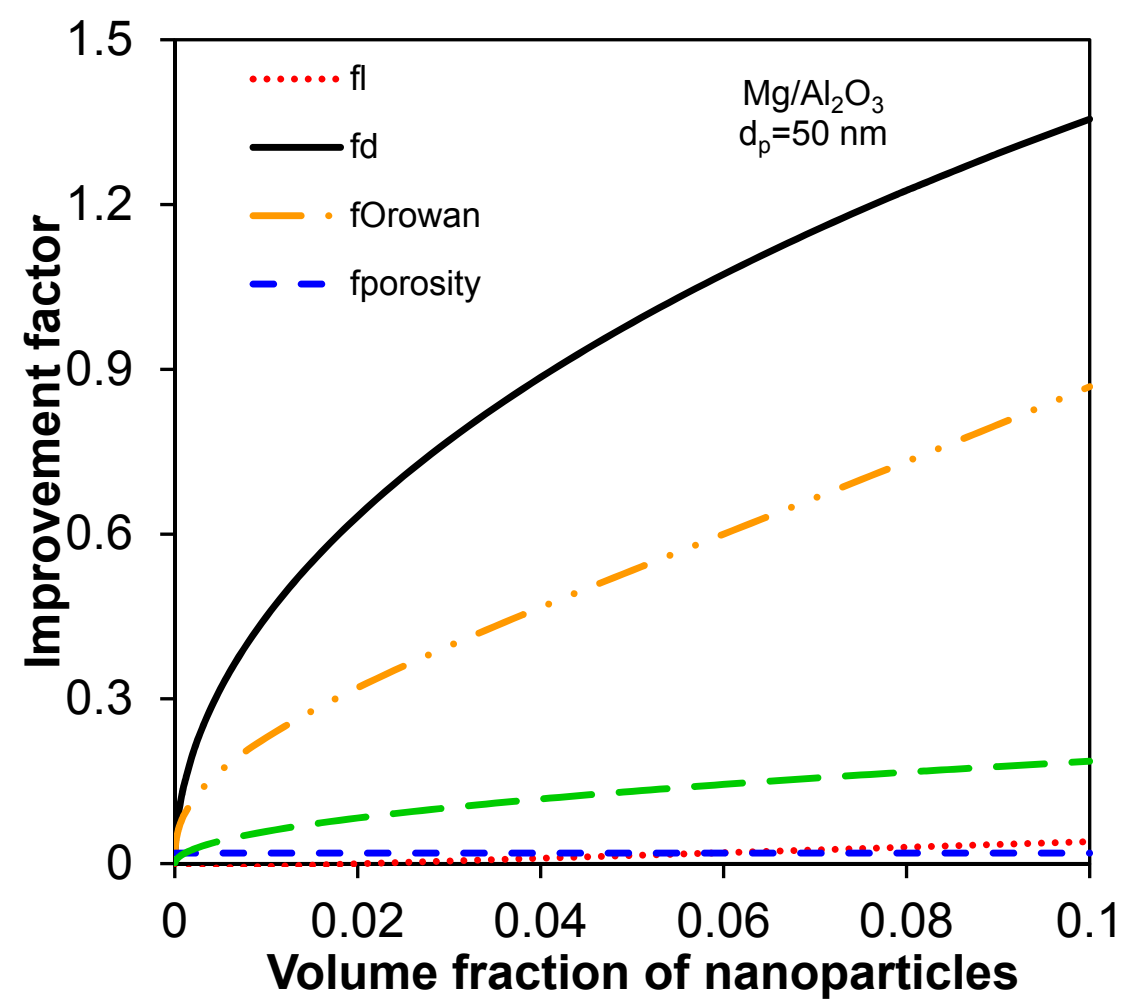

Figure 3. The improvement factors as a function of volume fraction of nanoparticles with a particle size of $50 \mathrm{~nm}$ and a volume fraction of 0.01 for porosity in $\mathrm{Mg} / \mathrm{Al}_{2} \mathrm{O}_{3}$ nanocomposites.

To further indicate the changes of the yield strength of MMNCs with the volume fraction of nanoparticles $\left(V_{\mathrm{p}}\right)$, the same set of data for the $\mathrm{Al}_{2} \mathrm{O}_{3}$-reinforced $\mathrm{Mg}$ nanocomposites tested at room temperature in reference [46] is selected here, which was originally from Gupta and co-workers [11,12] together with the relevant values from Brassell et al. [29]: $\sigma_{\mathrm{ym}}=97 \mathrm{MPa}, G_{\mathrm{m}}=16.5 \mathrm{GPa}, b=0.32 \mathrm{~nm}$, $\alpha_{\mathrm{m}}=28.4 \times 10^{-6}\left({ }^{\circ} \mathrm{C}\right)^{-1}, \alpha_{\mathrm{p}}=7.4 \times 10^{-6}\left({ }^{\circ} \mathrm{C}\right)^{-1}, \mathrm{~T}_{\text {process }}=300{ }^{\circ} \mathrm{C}, \mathrm{T}_{\text {test }}=20^{\circ} \mathrm{C}, \mathrm{M}=3.06, k=70 \mathrm{MPa} \sqrt{ } \mu \mathrm{m}$, $d_{\mathrm{p}}=50 \mathrm{~nm}, K=0.05$ [54,56], and $n=1.94$ (according to Equation (4a) for equiaxed particles where $l$ is equal to $d_{\mathrm{p}}$ ). In view of the change of porosity amount present in different composite fabrication processes, e.g., 0.07-1.04 vol\% [12], 0.25-1.15 vol\% [14], 3-12 vol\% [29], 0-1.18 vol\% [34], up to $12.25 \mathrm{vol} \%$ [32], about $6 \mathrm{vol} \%$ [57], up to $13 \mathrm{vol} \%$ [33], and up to $12.45 \mathrm{vol} \%$ [58], three typical porosity values of $1 \mathrm{vol} \%, 3 \mathrm{vol} \%$, and $5 \mathrm{vol} \%$ were selected in the present model calculation.

To verify the validity of the present model with consideration of grain size and porosity, comparisons were made between the model prediction and experimental data of three types of $\mathrm{Mg}$-based nanocomposites containing $\mathrm{Al}_{2} \mathrm{O}_{3}$, carbon nanotube (CNT), and $\mathrm{Y}_{2} \mathrm{O}_{3}$, respectively. Prior to doing so, a comparison between the present model prediction and those in the literature $[10,15,20,59-63]$ is shown in Figure 4. It is seen that the present model shows a similar trend to those of other models, and lies indeed in-between the other models. 


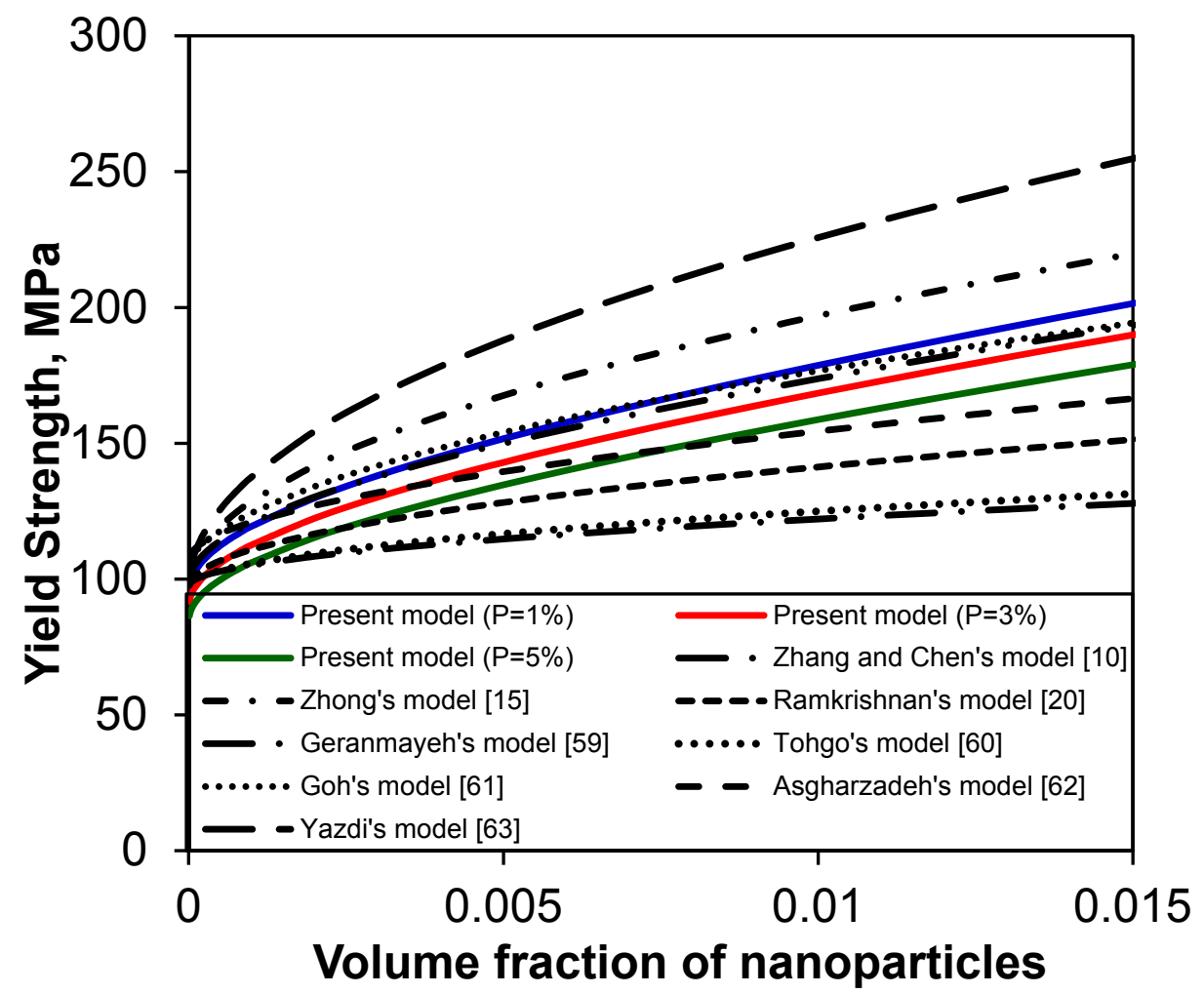

Figure 4. Comparison of the present model with different models reported in literature [10,15,20,59-63].

First, the yield strength predicted for carbon nanotube (CNT)-reinforced $\mathrm{Mg}$ nanocomposites is shown in Figure 5, together with the experimental data reported in refs. [14,16-18]. In the calculation of yield strength from Equation (11) the following data for the CNT-reinforced Mg nanocomposites tested at room temperature were used $[11,12,29]: \sigma_{\mathrm{ym}}=97 \mathrm{MPa}, G_{\mathrm{m}}=16.5 \mathrm{GPa}, b=0.32 \mathrm{~nm}, \alpha_{\mathrm{m}}=28.4 \times 10^{-6}\left({ }^{\circ} \mathrm{C}\right)^{-1}$, $\alpha_{\mathrm{p}}=-1.52 \times 10^{-6}\left({ }^{\circ} \mathrm{C}\right)^{-1}$ (thermal contraction of CNT occurred, leading to a negative $\alpha$ value [64]), $\mathrm{T}_{\text {process }}=350{ }^{\circ} \mathrm{C}, \mathrm{T}_{\text {test }}=20^{\circ} \mathrm{C}, K=0.05[54,56], n=1.94$ (for equiaxed particles), $d_{\mathrm{p}}=30 \mathrm{~nm}, P=1 \%$, $3 \%$ and $5 \%$. As shown in Figure 5, due to the considerations of porosity weakening effect and grain growth retardation by dispersed-particle-pinning of grain boundaries, the predicted yield strength for $P=1 \%, 3 \%$ and $5 \%$ in the present model lies almost in-between those of Zhang and Chen [10,21] and Ramakrishnan's [20] model.

However, the predicted yield strength in a lower porosity level shows a better agreement with Zhang and Chen's model [10,21]. The first and second experimental data were slightly lower and higher than that predicted from all methods including the present model, since all nanoparticles were assumed to be spherical like Zhang and Chen model [10,21]. The scatter of the experimental data might also be related to the waviness (or curviness) and agglomeration of CNTs [17,18,64-66], since the uniform dispersion of such tiny nano-sized particles in nanocomposites still poses a significant challenge [65]. Next, four data points showed a close agreement with the present model. It follows that incorporating the effects of porosity and dispersed-particle-pinning of grain growth in the analytical models could improve the predictability. 


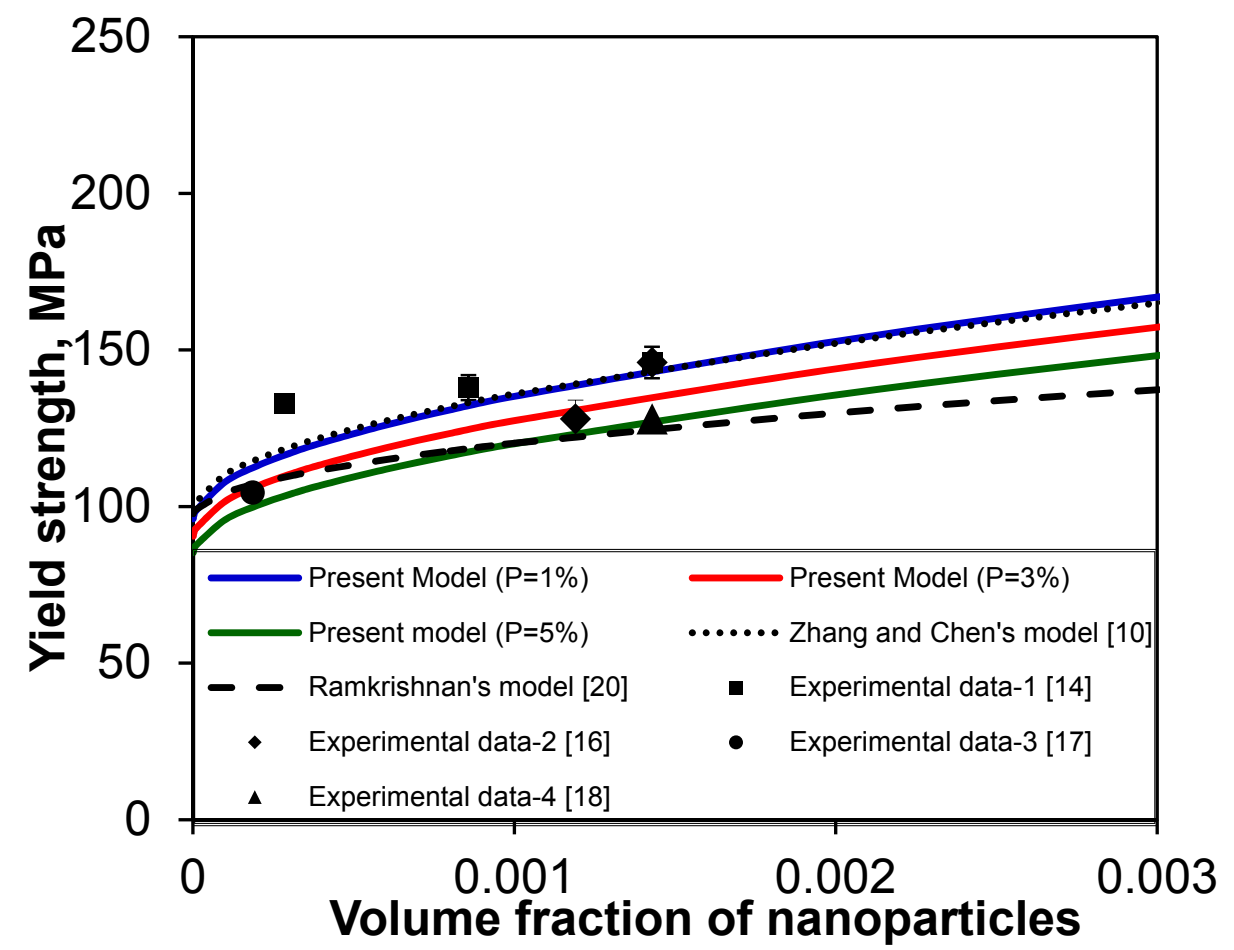

Figure 5. Comparison of the present model (solid curves) with the experimental data reported in [14,16-18], along with Zhang and Chen's model [10] and Ramakrishnan's model [20], for CNT-reinforced Mg nanocomposites.

To further examine the trend of the yield strength of MMNCs, another prediction of yield strength for $\mathrm{Al}_{2} \mathrm{O}_{3}$-reinforced $\mathrm{Mg}$ nanocomposites is shown in Figure 6, together with the experimental data reported in References [11,12,66-69]. The same set of data for the $\mathrm{Al}_{2} \mathrm{O}_{3}$-reinforced $\mathrm{Mg}$ nanocomposites tested at room temperature in reference [46] is first selected here, which was originally from Gupta and co-workers [11,12] together with the relevant values from Brassell et al. [29]: $\sigma_{\mathrm{ym}}=97 \mathrm{MPa}, G_{\mathrm{m}}=16.5 \mathrm{GPa}$, $b=0.32 \mathrm{~nm}, \alpha_{\mathrm{m}}=28.4 \times 10^{-6}\left({ }^{\circ} \mathrm{C}\right)^{-1}, \alpha_{\mathrm{p}}=7.4 \times 10^{-6}\left({ }^{\circ} \mathrm{C}\right)^{-1}, T_{\text {process }}=300^{\circ} \mathrm{C}, T_{\text {test }}=20^{\circ} \mathrm{C}, \alpha=0.3, \alpha_{1}=0.35$, $\beta=1.25, \varphi=6$ for $\mathrm{Mg}, k=70 \mathrm{MPa} \sqrt{\mu \mathrm{m}}, d_{\mathrm{p}}=50 \mathrm{~nm}, K=0.05$ [54,56], $n=1.94$ (according to Equation (4a) for equiaxed particles), and $P=1 \%, 3 \%$ and 5\%. Again, the yield strength predicted via the present model is in fairly good agreement with the experimental data reported in references [11,12,66-69]. Furthermore, with a higher amount of nanoparticles the dependence of the yield strength on the volume fraction of porosity became stronger. The scatter of the experimental data shown in Figure 6 would be associated with the processing techniques and conditions/parameters during the fabrication of $\mathrm{Mg}-\mathrm{Al}_{2} \mathrm{O}_{3}$ nanocomposites [11,12,66,67].

A further comparison involves $\mathrm{Y}_{2} \mathrm{O}_{3}$ particulate-reinforced Ti nanocomposite, as shown in Figure 7, in which the following parameters were used in the calculation [70-73]: $\sigma_{\mathrm{ym}}=450 \mathrm{MPa}, G_{\mathrm{m}}=44.8 \mathrm{GPa}$, $b=0.29 \mathrm{~nm}, \alpha_{\mathrm{m}}=11.9 \times 10^{-6}\left({ }^{\circ} \mathrm{C}\right)^{-1}, \alpha_{\mathrm{p}}=9.3 \times 10^{-6}\left({ }^{\circ} \mathrm{C}\right)^{-1}, T_{\text {process }}=827^{\circ} \mathrm{C}$ for particle size $d_{\mathrm{p}}=10,12$, 20, and $22 \mathrm{~nm}$ and $T_{\text {process }}=900^{\circ} \mathrm{C}$ for particle size $d_{\mathrm{p}}=10,40$, and $170 \mathrm{~nm}, T_{\text {test }}=20^{\circ} \mathrm{C}, K=0.05[54,56]$, $n=1.94$ (for equiaxed particles), $P=1 \%$.

On the basis of the values of the weight fraction given in [70], the following converted values of volume fraction/percent $V_{\mathrm{p}}=0.25 \%, 0.27 \%, 0.38 \%, 0.41 \%, 0.54 \%$, and $0.59 \%$ were utilized. The straight line with a slope of $m=1$ was drawn to show the value deviation. It is seen from Figure 7 that 
the present model with the consideration of both dispersed-particle-pinning of grain boundaries and porosity predicts the yield strength of the $\mathrm{Ti}^{-} \mathrm{Y}_{2} \mathrm{O}_{3}$ nanocomposites fairly nicely, where a combined effect of varying volume fraction of nanoparticles, thermo-mechanical treatment, and microstructures has been taken into consideration.

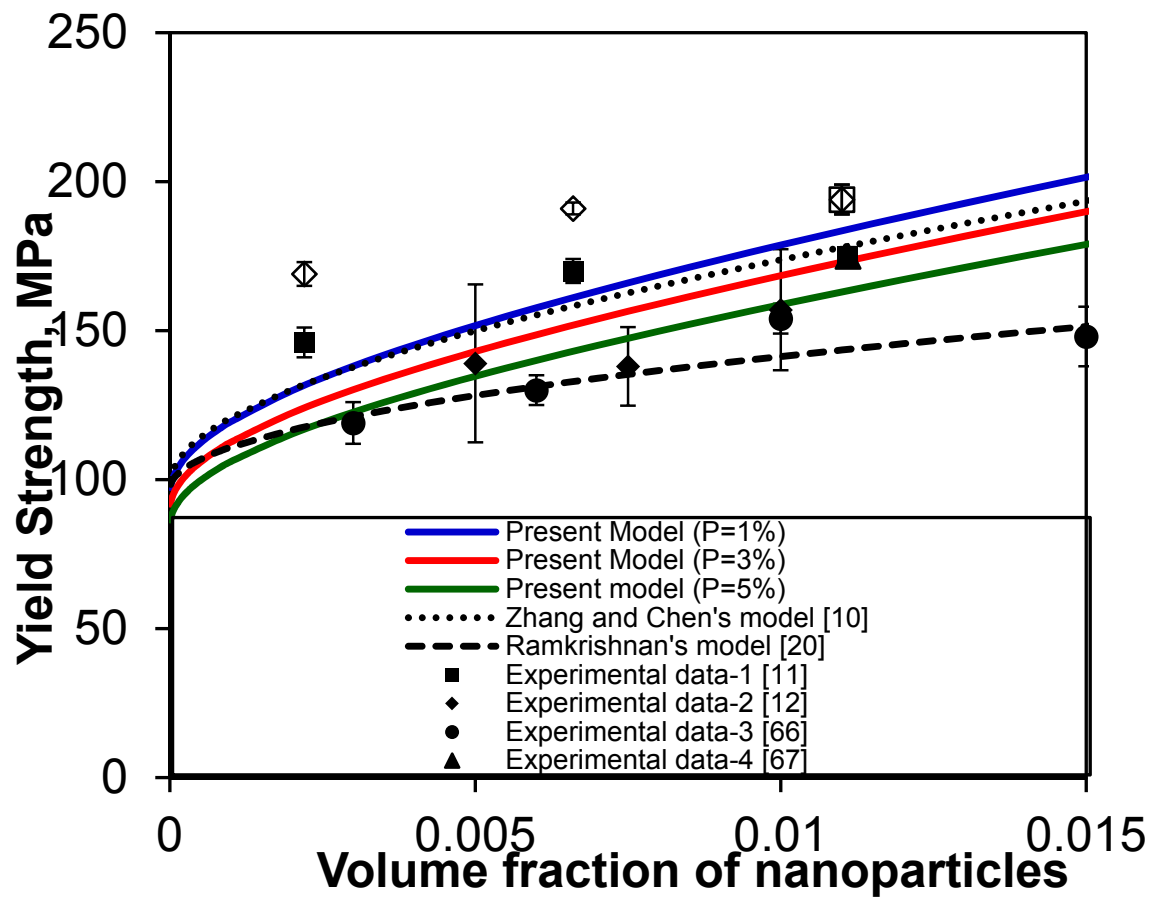

Figure 6. Comparison of the present model (solid curves) with the experimental data reported in references [11,12,66-69], in conjunction with Zhang and Chen's model [10] and Ramakrishnan's model [20], for $\mathrm{Al}_{2} \mathrm{O}_{3}$-reinforced $\mathrm{Mg}$ nanocomposites tested at $20{ }^{\circ} \mathrm{C}$.

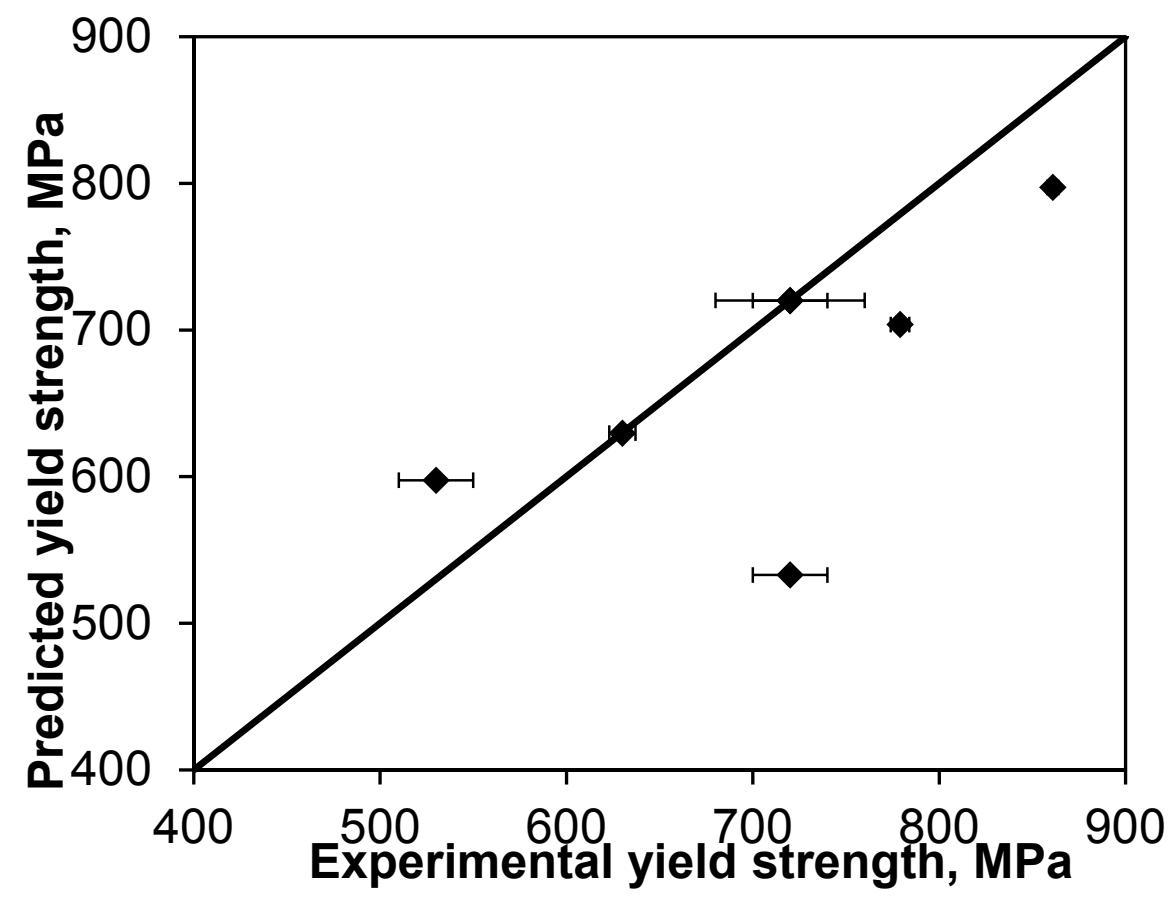

Figure 7. A comparison of the prediction via the present model with the experimental data of $\mathrm{Y}_{2} \mathrm{O}_{3}$-reinforced Ti nanocomposites tested at $20^{\circ} \mathrm{C}$. 


\section{Conclusions}

While it was confirmed that the Orowan strengthening plays a significant role in MMNCs, the above comparisons between the present model prediction and the experimental data reported in the literature corroborate that both the positive and fairly strong effect of grain size refinement (or Hall-Petch equation) and the negative effect of porosity should also be taken into consideration in predicting the yield strength of MMNCs, although the effect of a small amount of porosity is rather small. The Zener pinning effect of grain boundaries by the nano-sized particles has been integrated into the present modelling as well. The proposed model has been validated using the experimental data of a number of MMNCs containing different types of nano-sized particles, and it shows fairly good agreement. This suggests that the positive effects of the Orowan strengthening mechanism, enhanced dislocation strengthening mechanism and load-bearing effect of the reinforcement, and grain size effect, as well as the negative weakening effect of porosity all need to be considered.

\section{Acknowledgments}

The authors would like to thank the financial support provided by the Natural Sciences and Engineering Research Council of Canada (NSERC), Premier's Research Excellence Award (PREA), NSERC-DAS Award, AUTO21 Network of Centers of Excellence, and Ryerson Research Chair program for providing financial support. The helpful discussion with Sanjeev Bhole is gratefully acknowledged. This paper is presented at the 20th International Conference on Composite Materials (ICCM20), Copenhagen, Denmark, July 19-24, 2015.

\section{Author Contributions}

F.A.M. and D.L.C. conceived, analyzed the data, and wrote the paper.

\section{Conflicts of Interest}

The authors declare no conflict of interest.

\section{References}

1. Pollock, T.M. Weight loss with magnesium alloys. Science 2010, 328, 986-987.

2. Chu, S.; Majumdar, A. Opportunities and challenges for a sustainable energy future. Nature 2012, 488, 294-303.

3. Zheng, X.Y.; Lee, H.; Weisgraber, T.H.; Shusteff, M.; DeOtte, J.; Duoss, E.B.; Kuntz, J.D.; Biener, M.M.; Ge, Q.; Jackson, J.A.; et al. Ultralight, ultrastiff mechanical metamaterials. Science 2014, 344, 1373-1377.

4. Nie, J.F.; Zhu, Y.M.; Liu, J.Z.; Fang, X.Y. Periodic segregation of solute atoms in fully coherent twin boundaries. Science 2013, 340, 957-960.

5. Underwood, E. Models predict longer, deeper U.S. droughts: Future western "megadroughts" could be worse than ever. Science 2015, 347, 707.

6. McNutt, M. Climate change impacts. Science 2013, 341, 435. 
7. Schmale, J.; Shindell, D.; von Schneidemesser, E.; Chabay, I.; Lawrence, M. Air pollution: Clean up our skies. Nature 2014, 515, 335-337.

8. Luo, A.A. Magnesium: Current and potential automotive applications. JOM 2002, 54, 42-48.

9. Kainer, K.U. Magnesium-Alloys and Technology; Wiley-VCH Verlag GmbH \& Co. KGaA: Weinheim, Germany, 2003.

10. Zhang, Z.; Chen, D.L. Consideration of Orowan strengthening effect in particulate-reinforced metal matrix nanocomposites: A model for predicting their yield strength. Scr. Mater. 2006, 54, 1321-1326.

11. Hassan, S.F.; Gupta, M. Development of high performance magnesium nanocomposites using solidification processing route. Mater. Sci. Tech. 2004, 20, 1383-1388.

12. Wong, W.L.E.; Karthik, S.; Gupta, M. Development of hybrid $\mathrm{Mg} / \mathrm{Al}_{2} \mathrm{O}_{3}$ composites with improved properties using microwave assisted rapid sintering route. J. Mater. Sci. 2005, 40, 3395-3402.

13. Han, B.Q.; Dunand, D.C. Microstructure and mechanical properties of magnesium containing high volume fractions of yttria dispersoids. Mater. Sci. Eng. A 2000, 277, 297-304.

14. Goh, C.S.; Wei, J.; Lee, L.C.; Gupta, M. Development of novel carbon nanotube reinforced magnesium nanocomposites using the powder metallurgy technique. Nanotechnology 2006, 17, 7-12.

15. Zhong, X.L.; Wong, W.L.E.; Gupta, M. Enhancing strength and ductility of magnesium by integrating it with aluminum nanoparticles. Acta Mater. 2007, 55, 6338-6344.

16. Goh, C.S.; Wei, J.; Lee, L.C.; Gupta, M. Effects of fabrication techniques on the properties of carbon nanotube reinforced magnesium. Solid State Phenom. 2006, 111, 179-182.

17. Liu, S.Y.; Gao, F.P.; Zhang, Q.Y.; Zhu, X.; Li, W.Z. Fabrication of carbon nanotubes reinforced AZ91D composites by ultrasonic processing. Trans. Nonferr. Met. Soc. China 2010, 20, 1222-1227.

18. Goh, C.S.; Wei, J.; Lee, L.C.; Gupta, M. Simultaneous enhancement in strength and ductility by reinforcing magnesium with carbon nanotubes. Mater. Sci. Eng. A 2006, 423, 153-156.

19. Tun, K.S.; Gupta, M. Improving mechanical properties of magnesium using nano-yttria reinforcement and microwave assisted powder metallurgy method. Comp. Sci. Technol. 2007, 67, 2657-2664.

20. Ramakrishnan, N. An analytical study on strengthening of particulate reinforced metal matrix composites. Acta Mater. 1996, 44, 69-77.

21. Zhang, Z.; Chen, D.L. Contribution of Orowan strengthening effect in particulate-reinforced metal matrix nanocomposites. Mater. Sci. Eng. A 2008, 483-484, 148-152.

22. Nardone, V.C.; Prewo, K.M. On the strength of discontinuous silicon carbide reinforced aluminum composites. Scr. Metall. 1986, 20, 43-48.

23. Moghadam, A.D.; Schultz, B.F.; Ferguson, J.B.; Omrani, E.; Rohatgi, P.K.; Gupta, N. Functional metal matrix composites-self-lubricating, self-healing, and nanocomposites-An outlook. JOM 2014, 66, 872-881.

24. Lurie, S.; Belov, P.; Volkov-Bogorodsky, D.; Tuchkova, N. Nanomechanical modeling of the nanostructures and dispersed composites. Comp. Mater. Sci. 2003, 28, 529-539.

25. Lin, K.; Law, E.; Pang, S. Effects of interphase regions of particulate-reinforced metal matrix nanocomposites using a discrete dislocation plasticity model. J. Nanomech. Micromech. 2014, doi:10.1061/(ASCE)NM.2153-5477.0000098.

26. Meenashisundaram G.K.; Gupta, M. Synthesis and characterization of high performance low volume fraction $\mathrm{TiC}$ reinforced $\mathrm{Mg}$ nanocomposites targeting biocompatible/structural applications. Mater. Sci. Eng. A 2015, 627, 306-315. 
27. Park, M.S. An enhanced mean field material model incorporating dislocation strengthening for particle reinforced metal matrix composites. J. Mech. Sci. Tech. 2014, 28, 2587-2594.

28. Bocchini, G.F. The influence of porosity on the characteristics of sintered materials. Int. J. Pow. Metal. 1986, 22, 185-186.

29. Brassell, G.W.; Horak, J.A.; Butler, B.L. Effects of porosity on strength of carbon-carbon composites. J. Comp. Mater. 1975, 9, 288-296.

30. Ray, S. Synthesis of cast metal matrix particulate composites. J. Mater. Sci. 1993, 28, 5397-5413.

31. Viswanathan, V.; Laha, T.; Balani, K.; Agarwal, A.; Seal, S. Challenges and advances in nanocomposite processing techniques. Mater. Sci. Eng. R 2006, 54, 121-285.

32. Ahmad, S.N.; Hashim, J.; Ghazali, M.I. Effect of porosity on tensile properties of cast particle reinforced MMC. J. Comp. Mater. 2005, 41, 575-589.

33. Molina, J.M.; Prieto, R.; Narciso, J.; Louis, E. The effect of porosity on the thermal conductivity of Al-12 wt. \% Si/SiC composites. Scr. Mater. 2009, 60, 582-585.

34. Zhong, X.L.; Gupta, M. Development of lead-free $\mathrm{Sn}-0.7 \mathrm{Cu} / \mathrm{Al}_{2} \mathrm{O}_{3}$ nanocomposite solders with superior strength. J. Phys. D Appl. Phys. 2008, 41, doi:10.1088/0022-3727/41/9/095403.

35. Thein, M.A.; Li, L.; On, L.M.; Liu, T.; Liu, Z.; Ringer, S.P. Creep behavior of in-situ formed aln reinforced $\mathrm{Mg}-5 \mathrm{Al}$ nanocomposite at low temperatures and low stresses. Nanosci. Nanotechnol. Lett. 2009, 1, 204-207.

36. Paul, B.; Banerji, P. Grain structure induced thermoelectric properties in PbTe nanocomposite, Nanosci. Nanotechnol. Lett. 2009, 1, 208-212.

37. Xiao, L.; Chen, D.L.; Chaturvedi, M.C. Shearing of gamma double prime precipitates and formation of planar slip bands in Inconel 718 during cyclic deformation. Scr. Mater. 2005, 52, 603-607.

38. Hall, E.O. The deformation and ageing of mild steel: III discussion of results. Proc. Phys. Soc. B 1951, 64, 747-753.

39. Petch, N.J. The cleavage strength of polycrystals. J. Iron Steel Inst. 1953, 173, 25-28.

40. Van Aken, D.C.; Krajewski, P.E.; Vyletel, G.M.; Allison, J.E.; Jones, J.W. Recrystallization and grain growth phenomena in a particle-reinforced aluminum composite. Metall. Mater. Trans. A 1995, 26, 1394-1405.

41. Doherty, R.D.; Hughes, D.A.; Humphreys, F.J.; Jonas, J.J.; Juul Jensen D.; Kassner, M.E.; King, W.E.; McNelley, T.R.; McQueen, H.J.; Rollett, A.D. Current issues in recrystallization: A review. Mater. Sci. Eng. A 1997, 238, 219-274.

42. Hassold, G.N.; Holm, E.A.; Srolovitz, D.J. Effects of particle size on inhibited grain growth. Scr. Metall. Mater. 1990, 24, 101-106.

43. Stearns, L.C.; Harmer, M.P. Particle-inhibited grain growth in $\mathrm{Al}_{2} \mathrm{O}_{3}-\mathrm{SiC}$ : I, experimental results. J. Am. Ceram. Soc. 1996, 79, 3013-3019.

44. Nishizawa, T.; Ohnuma, I.; Ishida, K. Examination of the Zener relationship between grain size and particle dispersion. Mater. Trans. JIM 1997, 38, 950-956.

45. Nes, E.; Ryum, N.; Hunderi, O. On the Zener drag. Acta Metall. 1985, 33, 11-22.

46. Mirza, F.A.; Chen, D.L. An analytical model for predicting the yield strength of particulate-reinforced metal matrix nanocomposites with consideration of porosity. Nanosci. Nanotechnol. Lett. 2012, 4 , 794-800. 
47. Shao, J.C.; Xiao, B.L.; Wang, Q.Z.; Ma, Z.Y.; Yang, K. An enhanced FEM model for particle size dependent flow strengthening and interface damage in particle reinforced metal matrix composite. Comp. Sci. Technol. 2011, 71, 39-45.

48. Dunand, D.C.; Mortensen, A. On plastic relaxation of thermal stresses in reinforced metals. Acta Metall. Mater. 1991, 39, 127-139.

49. Sankaranarayanan, S.; Nayak, U.P.; Sabat, R.K.; Suwas, S.; Almajid, A.; Gupta, M. Nano-ZnO particle addition to monolithic magnesium for enhanced tensile and compressive response. J. Alloys Compd. 2014, 615, 211-219.

50. Alizadeh, M.; Beni, H.A. Strength prediction of the $\mathrm{ARBed} \mathrm{Al} / \mathrm{Al}_{2} \mathrm{O}_{3} / \mathrm{B} 4 \mathrm{C}$ nano-composites using Orowan model. Mater. Res. Bull. 2014, 59, 290-294.

51. Akbarpour, M.R.; Salahi, E.; Hesari, F.A.; Kim, H.S.; Simchi, A. Effect of nanoparticle content on the microstructural and mechanical properties of nano-SiC dispersed bulk ultrafine-grained $\mathrm{Cu}$ matrix composites. Mat. Des. 2013, 52, 881-887.

52. Kim, C.-S.; Sohn, I.; Nezafati, M.; Ferguson, J.B.; Schultz, B.F.; Bajestani-Gohari, Z.; Rohatgi, P.K.; Cho, K. Prediction models for the yield strength of particle-reinforced unimodal pure magnesium (Mg) metal matrix nanocomposites (MMNCs). J. Mater. Sci. 2013, 48, 4191-4204.

53. Sanaty-Zadeh, A. Comparison between current models for the strength of particulate-reinforced metal matrix nanocomposites with emphasis on consideration of Hall-Petch effect. Mater. Sci. Eng. A 2012, 531, 112-118.

54. Saada, G. Hall-Petch revisited. Mater. Sci. Eng. A 2005, 400-401, 146-149.

55. Li, J.C.M. Petch relation and grain boundary sources. Trans. Metall. Soc. AIME 1963, 227, 239-247.

56. Louchet, F.; Weiss, J.; Richeton, T. Hall-Petch law revisited in terms of collective dislocation dynamics. Phys. Rev. Lett. 2006, 97, doi:10.1103/PhysRevLett.97.075504.

57. Liu, T.M.; Chao, C.G. Effect of magnesium on mechanical properties of alumina-fiber-reinforced aluminum matrix composites formed by pressure infiltration casting. Mater. Sci. Eng. A 1993, 169, 79-84.

58. Ahmad, S.N.; Hashim, J.; Ghazali, M.I. The effects of porosity on mechanical properties of cast discontinuous reinforced metal- matrix composite. J. Comp. Mater. 2005, 39, 451-466.

59. Geranmayeh, A.R.; Mahmudi, R.; Kangooie, M. High-temperature shear strength of lead-free $\mathrm{Sn}-\mathrm{Sb}-\mathrm{Ag} / \mathrm{Al}_{2} \mathrm{O}_{3}$ composite solder. Mater. Sci. Eng. A 2011, 528, 3967-3972.

60. Tohgo, K.; Itoh, Y.; Shimamura, Y. A constitutive model of particle-reinforced composites taking account of particle size effects and damage evolution. Comp. Part A 2010, 41, 313-321.

61. Goh, C.S.; Gupta, M.; Wei, J.; Lee, L.C. Characterization of high performance $\mathrm{Mg} / \mathrm{MgO}$ nanocomposites. J. Comp. Mater. 2007, 41, 2325-2335.

62. Asgharzadeh, H.; Simchi, A.; Kim, H.S. Hot deformation of ultrafine-grained $\mathrm{Al}_{6063 / \mathrm{Al}_{2} \mathrm{O}_{3}}$ nanocomposites. J. Mater. Sci. 2011, 46, 4994-5001.

63. Zehtab Yazdi, A.; Bagheri, R.; Zebarjad, S.M.; Razavi Hesabi, Z. Incorporating aspect ratio in a new modeling approach for strengthening of MMCs and its extension from micro to nano scale. Adv. Comp. Mater. 2010, 19, 299-316.

64. Kwon, Y.K.; Berber, S.; Tomanek, D. Thermal contraction of carbon fullerenes and nanotubes. Phys. Rev. Lett. 2004, 92, 015901-015904. 
65. Morsi, K.; Esawi, A. Effect of mechanical alloying time and carbon nanotube (CNT) content on the evolution of aluminum (Al) CNT composite powders. J. Mater. Sci. 2007, 42, 4954-4959.

66. Wong, W.L.E.; Gupta, M. Improving overall mechanical performance of magnesium using nano-alumina reinforcement and energy efficient microwave assisted processing route. Adv. Eng. Mater. 2007, 9, 902-909.

67. Hassan, S.F.; Tan, M.J.; Gupta, M. High-temperature tensile properties of $\mathrm{Mg} / \mathrm{Al}_{2} \mathrm{O}_{3}$ nanocomposite. Mater. Sci. Eng. A 2008, 486, 56-62.

68. Hassan, S.F.; Gupta, M. Effect of length of $\mathrm{Al}_{2} \mathrm{O}_{3}$ particulates on microstructural and tensile properties of elemental Mg. Mater. Sci. Eng. A 2006, 425, 22-27.

69. Hassan, S.F.; Gupta, M. Development of high performance magnesium nano-composites using nano- $\mathrm{Al}_{2} \mathrm{O}_{3}$ as reinforcement. Mater. Sci. Eng. A 2005, 392, 163-168.

70. De Castro, V.; Leguey, T.; Muñoz, A.; Monge, M.A.; Pareja, R. Relationship between hardness and tensile tests in titanium reinforced with yttria nanoparticles. Mater. Sci. Eng. A 2005, 400-401, 345-348.

71. Callister, W.D.; Rethwisch, D.G. Materials Science and Engineering: An Introduction, 9th ed.; John Wiley and Sons: New York, NY, USA, 2014.

72. Bever, M.B. Encyclopedia of Materials Science and Engineering; Pergamon Press: New York, NY, USA, 1986.

73. Kingery, W.D. Introduction to Ceramics, 2nd ed.; John Wiley and Sons: New York, NY, USA, 1976.

(C) 2015 by the authors; licensee MDPI, Basel, Switzerland. This article is an open access article distributed under the terms and conditions of the Creative Commons Attribution license (http://creativecommons.org/licenses/by/4.0/). 